\title{
Tumor necrosis factor receptor 1 associated periodic syndrome
}

INSERM

\section{Source}

INSERM. (1999). Orphanet: an online rare disease and orphan drug data base. Tumor necrosis factor receptor 1 associated periodic syndrome. ORPHA:32960

Tumor necrosis factor receptor 1 associated periodic syndrome (TRAPS) is a periodic fever syndrome, characterized by recurrent fever, arthralgia, myalgia and tender skin lesions lasting for 1 to 3 weeks, associated with skin, joint, ocular and serosal inflammation and complicated by secondary amyloidosis (see this term). 